Kenneth H. Solomon · C. M. Burt

\title{
Irrigation sagacity: a measure of prudent water use
}

\begin{abstract}
Within the western United States, water rights are granted for reasonable and beneficial water use, and a measure of irrigation performance that embodies this standard is needed. A new performance parameter, irrigation sagacity (IS), is recommended for this purpose. The term 'sagacity' comes from 'sagacious', meaning wise or prudent. IS is more closely tied to the water rights granted, and to the potential for water conservation and reallocation than is the traditional irrigation efficiency, which considers only beneficial uses. Sagacious uses are either beneficial, or non-beneficial but reasonable. Reasonable uses are those that, while not directly benefiting agronomic production within the boundaries of the water rights area, are nonetheless justified under prevailing conditions. Non-sagacious uses (non-beneficial and unreasonable) are those uses which are without economic, practical, or other justification. Determination of sagacity involves checking alternate irrigation practices for practical, technical, economic, and environmental feasibility. Feasibility includes the requirement for a reasonable implementation schedule for any new practices. Only if a feasible alternate using less water is found should a current practice be considered in any part non-sagacious. The results of a sagacity determination may vary depending on geographic scale, time frame, and perspective.
\end{abstract}

\section{Introduction}

Irrigation may constitute the greatest portion of regional water consumption. The need for water for competing purposes, including municipal, industrial, and environmental

\footnotetext{
K. H. Solomon $(\bowtie) \cdot C$. M. Burt

BioResource and Agricultural Engineering,

California Polytechnic State University,

San Luis Obispo, CA 93704, USA

e-mail: ksolomon@calpoly.edu

Fax: +1-805-7562626
}

uses, creates a tension which affects all water policy decision making today. It is important that all water users not only make wise and effective use of their water, but are able to justify their wise and effective use to competing water users, to the courts, and to the court of public opinion. Irrigation performance parameters are tools that can help to make this case (Burt et al. 1997; Molden 1997).

Even within the agricultural irrigation community there is competition, and often scarcity of supply, emphasizing the need for effective water use. Different irrigation equipment, systems, and practices compete with one another with regard to water consumption, capital cost, operation and maintenance costs, labor, and other factors. Irrigation performance parameters can provide a basis for these comparisons, and for selection between alternates.

Throughout the western United States, water rights are granted for reasonable and beneficial purposes. For example, the US Bureau of Reclamation is charged to ensure that

"... deliveries of Colorado River water to each Contractor will not exceed those reasonably required for beneficial use." (Part 47 of Title 43, Code of Federal Regulations)

To assess irrigation systems, practices, and competing uses, whether against each other, or against benchmark targets, engineers need an irrigation performance parameter that embodies the reasonable and beneficial standard.

The parameter irrigation efficiency (IE) has long been used to quantify beneficial use of irrigation water (ASCE 1978). Water is used beneficially if it contributes directly to the agronomic production of the crop. However, due to physical, economic, or managerial constraints, and various environmental requirements, some degree of non-beneficial use is generally reasonable. Therefore, an additional parameter is needed which incorporates quantification of reasonable uses: those uses that may not contribute to agronomic production, but are nonetheless justified under the particular circumstances at hand. The parameter irrigation sagacity (IS) was proposed by Solomon (1993) to quantify both reasonable and beneficial uses. The remainder of this paper will explore the concept of 'sagacity.' Reasonable and beneficial will receive technical definitions which can 
be applied uniformly across systems, practices and jurisdictions ${ }^{1}$. Issues with the application and interpretation of 'sagacity' will be discussed.

\section{Irrigation performance parameters}

Irrigation performance is quantified through the use of special parameters (ASCE 1978; Burt et al. 1997). They aid in planning and design by relating necessary supply volumes to net requirements, and by establishing targets useful in some design processes. They enable the comparison of systems and practices against alternatives, and against target or benchmark values. Parameters which embody the goals, objectives, and values of water policies and water users can be used to assess the extent to which irrigation systems and practices achieve those goals and objectives.

When water is applied to an irrigated area, portions of the total application arrive at various destinations. To identify and quantify these fractions, it is important to specify the boundaries around the area studied (Burt et al. 1995, 1997; Clemmens et al. 1995; Molden 1997). Only water crossing these boundaries, into or out of the area, or changes in the amount of stored water within the boundaries, may be counted. Flows and recirculation within the boundaries are ignored. Once quantified, the fractions of applied water that reach various destinations are assigned to certain categories, such as beneficial, consumed, reasonable, required. The sum of all fractions within a category constitutes a measure of performance (e.g., efficiency). No single parameter can fully describe irrigation performance. But a small number of terms, taken together, can yield useful information suitable for decision making (Burt et al. 1997).

\section{Irrigation efficiency}

A commonly used irrigation performance parameter is IE (Burt et al. 1997), which can be written in decimal form as:

$$
\begin{gathered}
\mathrm{IE}=\frac{\text { volume of irrigation water beneficially used }}{\text { volume of irrigation water applied }} \\
-\Delta \text { storage of irrigation water }
\end{gathered}
$$

IE counts in its numerator those portions of the irrigation water that are judged to be beneficially used. Beneficial uses are those that contribute directly to the agronomic production of the crop. Examples of beneficial uses include

\footnotetext{
1 The California Water Code (1997) recognizes irrigation as a beneficial use ( $(106)$. Water diverted for irrigation is beneficial $(\S 100)$. The amount of water that may be diverted is limited to that which is "reasonably required" $(\S 100)$. Legal usage of these words may vary in other jurisdictions. Therefore we have used the technical definitions recommended by Burt et al. (1997) which can be applied uniformly across jurisdictions.
}

crop evapotranspiration (ET), water harvested with the crop, water used for salt control (leaching), climate control, seedbed preparation, softening the soil crust for seedling emergence, and ET from beneficial plants (windbreak, cover crop, habitat for beneficial insects). Evaporation during regular and reclamation leaching, and evaporation during necessary irrigations are beneficial, since an agronomic objective is achieved during those events (Burt et al. 1997).

Examples of non-beneficial uses at the farm level include overirrigation due to non-uniformity, uncollected tailwater, deep percolation beyond that needed for salt removal, unnecessary evaporation from wet soil outside cropped area, spray drift beyond field boundaries, and evaporation associated with excessively frequent irrigations. At the irrigation district level, non-beneficial uses include spills, seepage, evaporation from canals or reservoirs, and ET from non-beneficial plants such as weeds and phreatophytes.

An alternative set of parameters and use categories has been proposed by Molden (1997). He uses the term water depletion for consumptive uses, and process depletion for beneficial consumptive uses. He identifies water consumed that does not contribute to agronomic objectives as nonprocess depletion. While he acknowledges non-consumptive (non-depletive) uses, his performance parameters do not include the category of beneficial, non-consumptive uses, such as water used for leaching to maintain a salt balance in the field.

IE as a concept has often been misapplied or misinterpreted (Brown 1992; Willardson et al. 1994). Failure to differentiate between consumptive and beneficial uses, or to properly treat reuse of tailwater or drainage, can lead to misunderstandings regarding IE (see Burt et al. 1997 for a thorough discussion of beneficial and consumptive uses). Improper treatment of tailwater or drainage reuse is often caused by failure to precisely specify the boundaries of the study area (Burt et al. 1995, 1997; Clemmens et al. 1995). Changes in the portions of irrigation water beneficially used or consumed at different geographic scales under conditions of reuse are explored quantitatively by Solomon and Davidoff (1997), and conceptually by Molden (1997).

It is a common misunderstanding that $(100-\mathrm{IE}) \%$ of the applied irrigation water represents the amount that is wasted and, therefore, the potential for conservation or reallocation. This is absolutely false: an IE of $75 \%$ does not mean that $25 \%$ of the applied irrigation water is wasted, nor does it mean that $25 \%$ of the applied irrigation water could be conserved and redirected elsewhere. As noted above, some degree of non-beneficial use is generally reasonable, so the potential for conservation and reallocation consists only of water uses that are both non-beneficial and unreasonable. Use of the IS parameter (defined below), which incorporates both beneficial and reasonable uses, would turn the preceding intuitive, yet false statement involving IE into one that is at once accurate, intuitive and appealing involving IS: the potential for conservation and reallocation is limited to (100-IS)\% of the applied irrigation water. 


\section{Irrigation sagacity}

Some performance parameter which incorporates the combined standards of beneficial and reasonable uses is needed. Water use needs to be evaluated in a manner consistent with the specification of water rights. Water uses that are beneficial and reasonable should be credited, while those that are neither, that are without reasonable justification, should not.

In suggesting IS as such a parameter, Solomon (1993) recommended a word that (1) carried an appropriate literal meaning, and (2) was unusual enough that it would be received neutrally by the listener, without prejudice, bias, or preassumed meaning. The term sagacity comes from sagacious, meaning wise or prudent. Of the term sagacious, Grove (1993, p. 2107) states:

"SAGACIOUS may connote wisdom, penetration, discernment, farsightedness and, above all, keen mature judgment."

IS may be defined as (Solomon 1993; Burt et al. 1997):

$$
\mathrm{IE}=\frac{\begin{array}{c}
\text { volume of irrigation water used beneficially } \\
\text { or reasonably }
\end{array}}{\begin{array}{c}
\text { volume of irrigation water applied } \\
-\Delta \text { storage of irrigation water }
\end{array}} \times 100 \%
$$

Thus, IS is based on a partition of irrigation water between uses that are sagacious (either beneficial or reasonable) or non-sagacious (neither beneficial nor reasonable). Reasonable uses are those that, while not directly benefiting agronomic production, are nonetheless reasonable under prevailing economic and physical conditions. Following are examples of water uses that, while not beneficial, are considered reasonable.

Losses which cannot be economically avoided

If canal seepage rates are low and it is not economical to line the canal to prevent that seepage, then the seepage is a reasonable, though non-beneficial, use. No irrigation system can be designed to apply water with perfect uniformity, so some deep percolation due to non-uniformity is a reasonable, though non-beneficial, use.

\section{Losses tied to technical requirements}

Reservoirs in the distribution system add flexibility and reduce canal spills. Evaporation from such reservoirs is a reasonable, though non-beneficial, use. Microirrigation systems generally require filtration, and filters need to be flushed periodically. Filter flush water may be a reasonable, though non-beneficial, use. If sprinkler irrigation is the appropriate technology, spray evaporation and wind drift losses are an inevitable consequence of using that technology to irrigate, and hence are a reasonable use.
Losses due to uncertainties

There are uncertainties associated with many aspects of water management. Exactly how much water is held in the soil? Exactly how much crop ET since the last irrigation? Exactly how much water is necessary for maintenance leaching? In the face of such uncertainties, it is reasonable for farmers to err on the side of overapplication, so some deep percolation due to uncertainty is a reasonable, though non-beneficial, use.

Losses which contribute towards environmental goals

If canal seepage feeds a wetlands or wildlife habitat area in a timely manner, that seepage may be deemed a reasonable, though non-beneficial, use. (Even though feeding a wetlands/habitat area meets environmental goals, it is not considered a beneficial use because it does not directly aid the production of the crop being irrigated.) If tailwater blends with drainage water to meet water quality standards in receiving waters, then that tailwater may be a reasonable, though non-beneficial, use.

Non-sagacious uses (neither beneficial nor reasonable) are those uses without economic, practical or other justification. An example of a non-sagacious use is wet soil and spray evaporation associated with excessively frequent irrigations. No agronomic objective is served by irrigating more frequently than needed, and it is difficult to imagine an economic justification for doing so. Hence, wet soil and spray evaporation associated with excessively frequent irrigations is without justification, is unreasonable, and nonsagacious. Tests for identifying non-sagacious uses are discussed in the next section. Figure 1 illustrates the various categories of water use and the parameters IE and IS. IS is a better measure of prudent water use than IE.

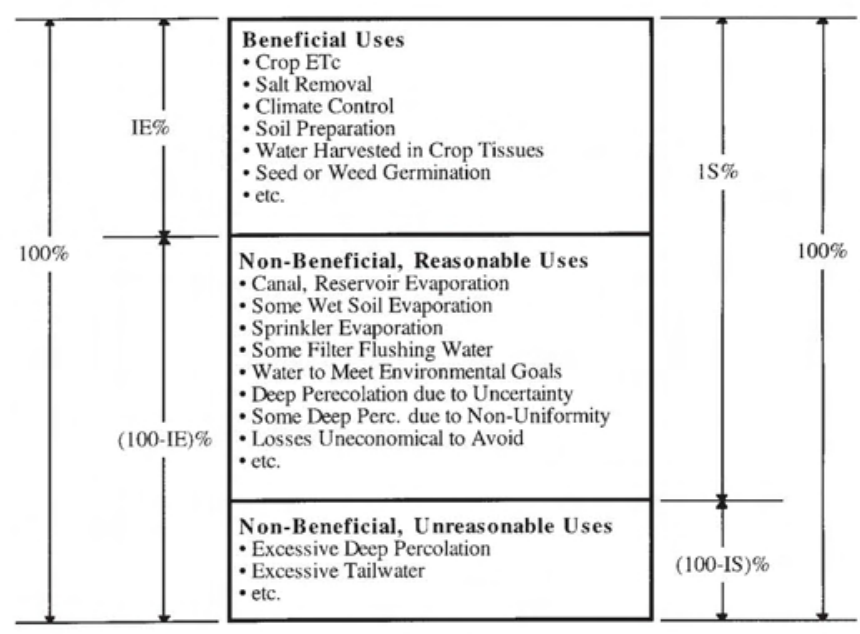

Fig. 1 Beneficial, reasonable, and unreasonable water uses. The height of the column represents $100 \%$ of the irrigation water applied (Adapted from Burt et al. 1997) 


\section{Discussion}

Application of the IS concept involves only a slight extension of the process used to determine IE. Boundaries are specified, flows into and out of the bounded area are quantified, fractions of the irrigation water flowing to various destinations are estimated, and judgments are made about whether those fractions are beneficial or reasonable. Whereas the determination of beneficial use involves only an agronomic criterion - direct contribution to the agronomic production of the crop - the determination of reasonable use involves more varied criteria.

To establish that a non-beneficial water use is reasonable involves the following steps.

1. Identify the practice(s) associated with that use.

2. Identify alternates to that practice that would involve reduced water use.

3. Check the feasibility of these alternate practices according to these four criteria:

3.1. Practical feasibility.

3.1.a. Observes all physical constraints.

3.1.b. Required resources are available.

3.1.c. Required information is available in a timely manner, without great uncertainty.

3.1.d. Realistic time schedule for implementation of alternate practice is planned.

3.2. Technical feasibility.

3.2.a. Required equipment is available and reliable.

3.2.b. Required software/plans are available and reliable.

3.2.c. Operational requirements can be met.

3.2.d. Phased transition into any new practice is planned.

3.3. Economic feasibility.

3.3.a. Benefits outweigh costs of changing from current to alternate practice.

3.3.b. Required financial resources (e.g., capital, credit, terms) are available.

3.3.c. Farmers are not required to assume greater downside risk.

3.3.d. Costs can be properly allocated to beneficiaries.

3.4. Environmental feasibility.

3.4.a. Existing environmental regulations are met.

3.4.b. The change must be environmentally benign or beneficial, or

3.4.c. The costs of any required environmental mitigation are considered.

4. The current practice is reasonable if no feasible alternate using less water exists.

5. The current practice is unreasonable if a feasible alternate using less water exists.

6. The amount of unreasonable (non-sagacious) use due to the current practice is the difference between the current use and the (reduced) use of the preferred alternate.

Practical feasibility considers physical constraints such as limitations due to climate, soil, terrain, water delivery schedules, water travel time, or other similar factors. Required resources can include labor (sufficient quantity and with suitable experience), infrastructure (e.g., maintenance of specialized equipment, extension advice on proposed crops) and information (precise knowledge, facts, data available when needed). Even after identifying the benefits of a new practice, there will be a lag time before implementation is possible. Decision makers need to be convinced, approvals obtained, plans drawn, financing arranged, and so forth. Thus practical feasibility includes the requirement for a realistic time schedule for implementation.

Technical feasibility has not only hardware but software and operational feasibility aspects. Equipment must be available, affordable, and reliable in an agricultural environment. It must satisfy requirements for accuracy and precision of flow, time or other quantities measured or controlled. Local, farm-scale demonstration projects may be necessary to prove that equipment and plans are reliable and operations feasible.

Economic feasibility is an obvious but complex test. It is not enough to compare the costs of operating one way to the costs of operating another way. The proposition facing a farmer is to change from one practice to another. The costs involved in abandoning an old practice and adopting a new one, or converting from the old to the new, may well be greater than the cost of starting the new practice from scratch. Further, even if the annualized cost of an alternate practice is favorable, it may not be possible for farmers to implement it unless additional resources such as financing and credit are available. Economic feasibility must also consider risk. It is not reasonable to ask farmers to undertake a large risk to actualize the potential of a small benefit.

As current events in the Imperial Irrigation District show (T. O'Halloran, personal communication), the ultimate beneficiary of water conservation efforts may be at some distance financially and geographically from the conservation efforts themselves. In this case, an urban water supply agency is benefiting from water conserved within an agricultural irrigation district. For this conservation to proceed, there must be a mechanism for transferring the costs of the conservation efforts out of the agricultural district to the urban agency which hopes to benefit from them. Economic feasibility must include plans and mechanisms for properly allocating the costs of alternate practices to those who will ultimately reap the benefit. This may be particularly difficult in the case of alternate practices whose ultimate beneficiary is the environment, since it is often not clear who "ought" to pay on behalf of an environmental common good.

The results of a sagacity determination may vary with geographic scale. Solomon and Davidoff (1997) cite one example where beneficial use changes with scale. Some deep percolation is beneficial for salt removal from individual fields. However, should this drainage water be reused on another field within a district, the beneficial credit to the individual field is forfeited at the district level, because the salt is reapplied within the district, and not removed from it. In other words, the sum of all field-scale beneficial leaching will exceed the beneficial use for the district as a whole, because some of the salt has to be leached more than once. The district-scale beneficial use for salt removal is limited by the total amount of salt removed from the district.

IS can also change with geographic scale because results of the various feasibility checks can change with scale. To a farmer, the district water delivery policies and schedule are a given. At the district level, these things may 
be considered adjustable. Districts can and should consider options that individual farmers cannot consider.

Economics and the ability to absorb risk also change with scale. What may not be economical to an individual farmer could be economical to a district, region or to another competing water user, if there is a way for them to share the costs as well as the benefits. While individual farmers are less able to bear risks due to uncertainty or reduced water use, the shift to a district or societal level offers the potential to "average" individual outcomes and pool risks. Because sagacity includes economics, which can change as markets and prices do, sagacity can change with time. Technology and the availability of resources are also factors influencing sagacity that can change over time. So sagacity is very much a site-, scale-, and time-specific quantity. Therefore, a necessary preliminary to the six steps cited above is this step 0 :

0 . Specify the particulars

0.1 . Boundaries and geographic extent of study area

0.2. Time frame for economic and technological determinations

0.3 . Perspective for feasibility checks (individual farmer, district, region, society?)

The foregoing shows that expanding our evaluations from efficiency (beneficial use) to sagacity (beneficial and reasonable use) requires an extension of criteria. Efficiency is defined in terms of agronomics, and may therefore be thought of as technical, objective, and fixed (in time). Sagacity depends on more far ranging criteria: economics, practicality, and environmental impact, all terms which may be thought of as social, political, subjective, and subject to change. The criteria (e.g., economic and technical feasibility) are fixed, but the results of the assessments may vary with time (for example, practices not currently feasible may become so at a later date). Some may argue on this basis that while efficiency falls within the scope of water management engineering, sagacity falls outside this scope and should be left up to political decision makers.

But resource law, which defines water rights in terms of beneficial and reasonable uses, does not allow this option. If water management engineers are to serve their agricultural constituents and the general public, they must make these determinations as best they can. There are none better qualified to do so. Engineering practice usually considers constraints, economics, tradeoffs, value judgments, and different objectives. A review of the ABET definition of engineering design indicates clearly that the determination of sagacity is not only within the scope of engineering, it is a tool by which engineers can better discharge their obligation to the public:

"Engineering design is the process of devising a system, component, or process to meet desired needs. It is a decision makingprocess ... in which the basic sciences and mathematics and engineering sciences are applied to convert resources optimally to meet a stated objective. Among the fundamental elements of the design process are the establishment of objectives and criteria, synthesis, analysis, construction, testing, and evaluation. The engineering design component ... must include most of [these] features: ... creativity, ... consideration of alternative solutions, feasibility considerations ..., and realistic constraints, such as economic factors, safety, reliability, aesthetics, ethics, and social impact." (ABET 1996. Engineering Criteria IV. C.3.d.(3)(c), p. 7)
An additional benefit of using IS rather than just IE is that it avoids some difficult technical problems in drawing the line between beneficial and non-beneficial uses. Two examples of this involve the evaporation component of crop ET, and bypass (preferential) flow.

Some would argue that only crop transpiration serves an agronomic objective, and qualifies as a beneficial use. Evaporation, they say, provides no agronomic benefit, and should be separated out as a non-beneficial use. Others argue it is difficult enough to determine the portion of irrigation water going to crop ET, let alone try to separate E and $\mathrm{T}$. This is further complicated by the fact that some portion of the $\mathrm{E}$ component substitutes for $\mathrm{T}$, by virtue of the fact that the $\mathrm{E}$ reduces available heat energy and increases humidity, reducing potential transpiration overall. To determine the amount of $\mathrm{E}$ that does not substitute for $\mathrm{T}$ and is thus non-beneficial is highly problematic.

Note, however, that whether or not some portion of $\mathrm{E}$ is considered non-beneficial, all crop ET is either beneficial or reasonable (evaporation associated with excessively frequent irrigations excluded, as noted before). The problematic partition, necessary to compute IE, is avoided altogether when computing IS.

A second example concerns water passing through cracks or large soil pores to a depth below the root zone (preferential or bypass flow). Such water may contribute little or nothing to either crop ET or leaching to maintain a salt balance in the root zone. Hence some would consider it non-beneficial. On the other hand, taking the broad view, this water may be considered beneficial. A volume of water is applied to a soil consisting of a wide range of pore sizes. Flow through the larger pore sizes will be more rapid and less efficient at salt removal than flow through smaller pore sizes. But it is impossible to determine just how much of the applied irrigation water passes the root zone so rapidly that it contributes to neither crop ET nor to salt removal. Further, this ill-defined amount of preferential flow is an unavoidable consequence of water applications to meet the agronomic objectives of irrigation and salt removal. Thus preferential flow should be regarded as beneficial.

The resolution to this dilemma is important if computing IE, but not when computing IS. Since it is generally economically and physically infeasible to prevent this preferential flow, it would be regarded as reasonable (sagacious), whether beneficial or not.

\section{Summary and recommendations}

Since water rights in the western United States are granted for reasonable and beneficial uses, an irrigation performance parameter that embodies the reasonable and beneficial standard is needed. IS, meaning wise and prudent use, is recommended for this purpose. IE, long used to quantify beneficial uses, is often misapplied or misinterpreted. A common misunderstanding is that (100-IE) $\%$ of the applied irrigation water represents the potential for conservation or reallocation. This is absolutely false. Because 
some degree of non-beneficial use is generally reasonable, the potential for conservation and reallocation consists solely of those water uses that are non-beneficial and unreasonable; that is, (100-IS)\% of the applied irrigation water. IS is a better measure of prudent water use than IE.

Sagacious uses are either beneficial, or non-beneficial but reasonable. Reasonable uses are those that, while not directly benefiting agronomic production, are nonetheless justified under prevailing conditions. Reasonable uses include losses which cannot be economically avoided, losses tied to technical requirements, losses due to uncertainties, and losses which contribute towards environmental goals. Non-sagacious uses (non-beneficial and unreasonable) are those uses which are without economic, practical, or other justification.

To establish that a non-beneficial water use is reasonable involves these steps: specify boundaries, time frame and perspective; identify associated practices and alternate practices with reduced water use; check the practical, technical, economic, and environmental feasibility of alternate practices. Feasibility includes the requirement for a reasonable implementation schedule for any new practices. The current practice is reasonable if no feasible alternate using less water exists. The current practice is unreasonable if a feasible alternate using less water does exists, and the amount of unreasonable (non-sagacious) use due to the current practice is the difference between the current use and the use of the preferred alternate. The results of a sagacity determination may vary depending on geographic scale, time frame, and perspective.

Sagacity depends on broader criteria than does efficiency. But resource law, which defines water rights in terms of beneficial and reasonable uses, requires that these broader criteria be addressed. If engineers are to fulfill their obligations to serve the public, they must make these determinations as best they can. It is usual for engineers to consider constraints, economics, tradeoffs, value judg- ments, and different objectives. There are none better qualified to do so.

\section{References}

ABET (1996) Criteria for accrediting programs in engineering in the United States. Engineering Accreditation Commission, Accreditation Board for Engineering and Technology, Baltimore, Md.

ASCE (1978) Describing irrigation efficiency and uniformity. J Irrig Drain Div ASCE 104(IR1)

Brown AL (1992) Sorting out new water, real water and paper water. UCLA Conference Buying and Selling Water in California, 12 November 1992, Los Angeles, Calif.

Burt CM, Clemmens AJ, Solomon KH (1995) Identification and quantification of efficiency and uniformity components. Proceedings First International Congress on Water Resources Engineering, 14-18 August 1995, San Antonio, Texas. American Society of Civil Engineers, New York, pp 1526-1530

Burt CM, Clemmens AJ, Strelkoff TS, Solomon KH, Bliesner RD, Hardy LA, Howell TA, Eisenhauer DE (1997) Irrigation performance measures - efficiency and uniformity. J Irrig Drain Eng ASCE 123:423-442

California Water Code (1997) § 100, § 106

Clemmens AJ, Strelkoff TS, Burt CM(1995) Defining efficiency and uniformity: problems and perspectives. Proceedings First International Congress on Water Resources Engineering, 14-18 August 1995, San Antonio, Texas. American Society of Civil Engineers, New York, pp 1521-1525

Grove PB (ed) (1993) Webster's third new international dictionary of the English language. Merriam-Webster, Springfield, Mass.

Molden D (1997) Accounting for water use and productivity. SWIM paper 1. International Irrigation Management Institute, Columbo, Sri Lanka

Solomon KH (1993) Technical memorandum. Center for Irrigation Technology, California State University, Fresno, Calif.

Solomon KH, Davidoff B (1997) Relating unit and subunit irrigation performance. Paper no. 97-2183, presented at the 1997 ASAE Annual International Meeting Tools for Transforming Tomorrow, Minneapolis, Minn., 10-14 August 1997

Willardson LS, Allen RG, Frederiksen HD (1994) Elimination of irrigation efficiencies. 13th Technical Conference, USCID, 19-22 November 1994, Denver, Colo. 